\title{
Application Study on New-Type Bamboo Materials in Space Design
}

\author{
Hongkun Peng ${ }^{a}$, Songliu Cao ${ }^{b}$ \\ Art Institute of Northeast Dianli University, 169\# Changchun road, Jilin, Jilin province, China \\ Penghongkun1199@163.com, 57132145@qq.com
}

Keywords: Bamboo culture, Bamboo material, Interior design, Green and environment protection

\begin{abstract}
For lack of wood material resources, with the application of bamboo's substitution for wood has great development potential. China is the first to use bamboo, and vigorously grow bamboo in the world. Bamboo culture has a long history in China and bamboo is one of the natural materials with the characteristic of the Chinese nation, meanwhile it is also renewable green resource. In this paper, through the analysis of the performance and characteristics of bamboo timber and the culture of bamboo, the feasibility and the key point of design that space design built by bamboo must be studied and investigated in depth.
\end{abstract}

\section{Introduction}

Our country is rich in bamboo resources, whether the planting numbers, areas, or accumulations, are among the forefront of the world, and has long been known as the bamboo kingdom. Traces of bamboo culture have a long history in China since ancient times. Bamboo can meet the material needs of people, involving food, clothing, shelter, line, etc. With the improvement of people's life quality, we began to pay more attention to living environment and health. And bamboo is a renewable green environmental material, easy degradation and fertility strong, and growth rate is more than wood. Reasonable use of bamboo not only can alleviate the shortage of wood resources, also can provide green interior space with the road of sustainable development.

\section{Feasibility of the bamboo}

Along with the wide application of modern materials, people ignored the traditional materials, the bamboo. For its practicality, safety, durability is not very understood. And the cognition of the use of bamboo is limited to ethnic minorities bamboo house building in Yunnan. Whether bamboo can applied to the large-scale city building materials and interior decoration, depend on the bamboo culture, the mechanics characteristics and the types of bamboo comprehensive discussion and people in the use of bamboo in the process of gradually deepening and reflection.

Bamboo Culture. Chinese bamboo culture has a long history, which can be traced back to Shang and Zhou Dynasties. Bamboo culture is closely tied to literature, painting, music, architectural structure, etc. There were many literati who praised and described bamboo widely in ancient poetry. Among the excavations, there are many bamboo products. Bamboo integrated into daily life, water conservancy, transportation, paper-making and other fields at ancient times. Due to it's toughness, tallness and straightness, compressive strength, and corrosion resistance, bamboo is an ideal building material and decorative material. Bamboo is used for furniture, sculpture and daily use. They are utilities but also artwork; it has artistic value and culture traits. In Chinese culture, bamboo is used widely. Within writing brushes, ink sticks, paper and ink-stones, brushes and paper are made of bamboo. In interior spaces, within bamboo furniture, either as big as bed, or as small as umbrella, we can see the figure of bamboo. Su Shi once said, I would rather eat no meat, than live without bamboo. No meat you may become thin, but without bamboo would be tacky. Bamboo is one of three friends of winter, but also a member of "four gentlemen". (The "Four gentlemen" consists of plum, orchid, bamboo,chrysanthemum in China. ) So bamboo is everywhere in our life. [1]

Mechanics Features of Bamboo. Bamboo is the basis of building and decorative material. Bamboo is light and has strong anti-pressure performance, ecerlent elasticity and toughness, which is 
hard to shrinkage and deform. After fabrication processing, bamboo would has strong rift grain comeprssive strength, strong compressive and tensile strength, and high ratio of mild and weight. Bamboo's physical performance is similar to steel, and bamboo has good mechanical performance. According to the research, the intensity of tension of bamboo is about three times of that of wood, and the intensity of pressure is about two times. The intensity of bamboo is better than other building material after steel. It is called steel in plant world. Two of the features of bamboo are its thick skin and the fact that it's hollow in the inside, which can keep out the strong hurricane and has strong bending rigidity. The growth characteristic of bamboo is bamboo joint. There is a joint every section, and the cross section of joint has a slice, of which surface is solid. It has resisting reinforcing effect to make bamboo stress evenly. The experimental results demonstrate that a section of bamboo with a joint has stronger bending rigidity than other on joint section. Because of the slice of itself, bamboo's lifetime is longer than woods under the situation of repeated bending deformation. [2]

Types of Bamboo. As people's living standards are improving ceaselessly, they begin to pursue a healthy and environmental life. Owing to the increasing demand of environmental-friendly material, our country's low forest coverage rate, and the demand of woods increases sharply with the rapid development of urbanization, we have to import woods massively to protect existing green resources. And because of bamboo's rich resources, short growing cycle, high utilization, and strong renewable abilities, bamboo's substitution for wood will help to resolve the contradiction between the supply and demand. As the developing of processing technology, the range of application of bamboo is expanding. It enter the filed of architecture and interior decoration material at a very rapid speed and become audience's building material with its features of featlow-carbon and environmental protection.

Raw Bamboo: the material of raw bamboo is mainly bamboo poles. The poles are processed into bamboo chip and tube. The moso bamboo used in bearing structure material has to be thick, tall, straight, and with low acuminate intensity. The bamboo used in indoor space decoration should be more slender to show its' rhyming beauty. Whether as bearing structure material or indoor space decorative material, the sense of hierarchy of lines of bamboo is very important. And we should choose the bamboo that has a great length of joints. It will be more comfortable on visual effect.

Bamboo-based Panel: Bamboo-based panel uses bamboo or a part of bamboo as the raw material. And then we're going to process, wipe out section, dry it, approaching rubber, form embryo, heat press, saw edge, etc. After these processes, the manufacture of bamboo-based panel is finished. The main types of bamboo-based panel are bamboo mat plywood, bamboo curtain plywood, bamboo plywood, bamboo particleboard, and so on. The manufacturing technique is simple and breaks through the original processing traditional craft. It keeps the texture of natural bamboo, makes rational use of the characteristics of bamboo fiber, and retains bamboo's physical properties like homogeneous material, Bamboo-based panel has been widely applied in the filed of building components.

Bamboo Laminated Timber: Bamboo laminated timber is suitable to select as the bamboo timber structure. It can be divided into two main types: planking and hew. It is processed bamboo after bonding compressing. The manufacture of bamboo laminated timber in our country is mature and stable, such as raw material processing technology, plate manufacture technology, support facilities for processing technology, etc. It has high yield and low production cost. Meanwhile laminated timber is suitable to apply in building structure material with its strong strength and stiffness.

\section{Development trend of bamboo}

Along with the green environmental protection, low carbon economy era, the bamboo developing a new way under the new processing technology. Low carbon environmental protection, renewable resources to replace disposable resources. Development of Bamboo that is low carbon and environmental protection has become a trend, and reduce of forest coverage has become increasingly important. Bamboo in the new production and use process begin to select the superior and eliminate the inferior, gradually achieve the new type of bamboo in the use of space design to reach green, 
health, environmental protection, low carbon efficiency. The composite processing, the physical properties and appearance of the bamboo cannot meet the needs of the space design at the same time. It must through a special processing and restructuring of bamboo to produce the various composite materials under specific requirements, give full play to the characteristics of bamboo and improve its performance. For example, Bamboo plywood, Bamboo restructuring, Bamboo curtain plywood, Bamboo laminated plate and other composite materials. The factory production, the application of traditional bamboo was simple, extensive, low technology contents, and bad quality guarantee and caused the secondary pollution to a certain extent. With the development of modern science and technology, people reproduce and reprocess those traditional and irregular bamboos, change the production technology and process, carry out mass production to produce ruled material, according to process proceed line production, complete all parts of material processing, proceed assembling, to have many forms, perfect in workmanship, while minimizing costs, increase the rate of bamboo material that is out of a new type of bamboo products. Transfer the notion and broaden the market. Timber production cycle is longer than the other, as a long-term use of building materials in building materials market. It is necessary to find substitute products. Bamboo products have characteristics like green, ecology, environmental protection and short production cycle, high application performance, so we should make rapid development and broaden production type. [3]

\section{Application of new-type bamboo materials in space design}

Bamboo is the material of architecture and indoor space design. Reasonable use of bamboo in indoor space not only can improve the indoor space environment, can also add cultural atmosphere. Past application of bamboo is mostly minority village and bamboo house, which a person can feel unique architectural form of minority and material, embodies the concept of green health.

Advantages of the bamboo. Bamboo material by its mature stability in the production processing is playing a role in building and indoor environment by the different ways. After full understanding its use, we may design a new type bamboo space, in line with the urban living environment. Designers try to use bamboo materials to decorate the interior in order to reflect its unique advantages. When technology gets mature, we can use bamboo as decorated material just need cut the bamboo into strips, cover the walls, ceiling and floor, and mixed with other materials to achieve the best effect. Flexibility, Bamboo has wide planting range, can be found easily, has low price, and can redecorate along with the change of design style. Economical efficiency, Bamboo growth cycle is short, the price is lower than wood, but the quality is not worse than wood, and durable. Safety, Bamboo has the characteristics of compression resistance, bending resistance, used in the building can be anti-seismic during an earthquake. Comfort, According to the growth characteristics of bamboo, its smooth surface has the features of permeability and heat resistance which give a person sense of comfort.

Application of bamboo in space design. The bamboo is not only used in interior decoration, also the outdoor application frequency is improving continually. Application is no longer limited to the formwork and scaffolding but gradually expand to the modern large-scale high-rise buildings, light housing, and bridge construction, such as our country's bamboo construction, model house "cross curtilage". This project is built as high grade residence, and meanwhile it can be regard as exhibition center. The unit cell of external form of cross curtilage is the cross between two rectangles, overlapping place belongs to indoor public space, and other spaces are all independent. Building material is bamboo plywood with features of light body, high strength, and the natural texture, can better merge with the surrounding environment. Overall structure of the building is glue bamboo material, and the main structure is gantry frame system, mainly adopts the keel pillars of two kinds of specifications, Size span is $3900 \mathrm{MM}^{*} 4200 \mathrm{MM} *(100 \mathrm{MM} * 200 \mathrm{MM})$, Keel interval is $1100 \mathrm{MM}$, through building keel column and metal connectors to connect, so it forms a complete bamboo frame structure. In space form design, "cross curtilage" apply pioneering and changed ways to extend the unit cell architectural space. The entire design uses the processes of extension, transformation, zoom and deformation that built the continuity of the architectural modeling. The whole architectural space 
plane is more like an organic growth grid, embedded in a variety of plants, better adapt to the surrounding environment and functional requirements. Bamboo, in the interior decoration materials, can be used for bamboo flooring, bamboo furniture and bamboo handicrafts and bamboo wall, and so on. [4]

The bamboo floor is a natural pattern from bamboo patchwork, its hardness is greater than the wooden floor, water imbibition is strong, and its crude fiber is anti-skid, anti-friction, meanwhile warm in winter and cool in summer, also the natural scent of bamboo can eliminate fatigue. Bamboo wall decoration is based on design style, and the construction is simple, cost is cheap, the whole structure is anti-moisture and anti-heat. Bamboo furniture is smooth, light, durable, and has certain practicability and beauty.

\section{Conclusion}

Bamboo has the characteristics of environmental protection, short production cycle, high compressive strength and bending strength. New type bamboo made improvement in technology, decorate in vision, and other aspects like ecological, economic and social ethics. Not only bamboo can replace wood, reduce the use of forest resources, but, bamboo can also be completely constructed to architectural space and furniture with modern aesthetic consciousness, replace traditional interior decoration materials, improve design concept. Actively promote and widespread the use of bamboo, and design and construct the modern space, achieve sustainable business model, increase the proportion of bamboo in market share, use bamboo mechanical property, to reduce dependence on timber imports, achieve bamboo's substitution for wood is one path to go on sustainable path.

\section{References}

[1] Y. Xiao, G. Chen. The research and application of lightweight frame houses of bamboo structure. Building Structure Journal, 2010(6):195-199

[2] W.J. Luan, Tan Ruiguang. Research of new type bamboo space design. Popular Literature, 2011.(8): 125-126

[3] Y. Zhu, Y. Chen. The basic properties and application status of new building materials. Architecture Practice, 2014.(3):56-59

[4] G.P. Ren. Analysing the application of bamboo material in interior design. Technology And Design, 2010.(5): 21-22 